to make up the sum and substance of this plan of treatment. Hofmeier's recently published monograph on Prof. Schroder's too laparotomies (the number now is considerably more than that), may be studied with advantage.

Extirpation of the Cancerous Uterus through the Vagina.-Operating after his own plan, I have seen Dr. Martin make this extirpation in forty minutes without losing any blood-or at least without losing but very little. The operation is, however, a difficult one, and would be impossible in a constricted vagina, or if the uterus were very much enlarged. It is not easy to get the finger up through the posterior opening at the vaginal insertion, and unite the ligamentum lata with the peritoneum and vaginal wall, and even in the first stitches which unite the peritoneum with the posterior vaginal arch, the operator may fail, as others have done, to include the peritoneum. It is well to cut with one sweep of the scalpel directly into the cul-de-sac of Douglas, and then unite these cut surfaces-peritoneum and vagina-before going any further. The stitches must be drawn as tightly as possible, and Dr. Martin is in the habit of using about four of them. A double thread is used with the lig. lata, and the needle should come out about one ctm. from where it went in. This requires nice manipulation, and the index finger must be delicate in its sense of touch. The great merit of this operation is that it is rapidly done, and with the loss of the smallest possible amount of blood.

After-Treatment.-In plastic operations upon the vagina or upon the cervix, if aseptic silk be used, there is no necessity for further interference. In lacerations of the perineum, the stitches can be removed in a week. The vagina can be packed with iodoform gauze (gauze well soaked in iodoform and glycerine), the parts having been powdered with iodoform immediately after the operation. When changing the dressings, it is a good plan to irrigate thoroughly with carbolized water. When the vagina is not tamponed, warm antiseptic injections should be kept up daily. This should be carefully done, so that the nozzle of the syringe will not irritate the cervix, and the reservoir and receiver should be so arranged that the woman can lie in bed with the hips elevated, and allow the injection to go on for half an hour at a time. After amputations of the cervix, there is often a good deal of posterior inflammation, which resists treatment for a long time and is wearing upon the patient. This yields in time to patience and hot water injections. The bowels must be kept soluble. Constipation, a prevalent complaint among women, keeps up the inflammation, and each passage is attended with severe pain. After laparotomies, careful nursing and judicious feeding are of primary importance. Morphia should be given at first as occasion may require, and the bladder should be emptied by the nurse until the woman can safely do so herself. When indicated, an ice-bladder over the abdomen is frequently called into requisition in Germany. For the first few days, milk, wine and water and bouillon may be given-but nothing should be forced upon the patient for some hours after the operation. Mellin's Food subserves a useful purpose, as it furnishes heat, and can be retained by the most delicate stomach. From the fourth to the seventh day, a little meat may be added. The drainage tube may be removed upon the third or fourth day. All dressings should be renewed under the fullest antiseptic precautions.

Abdominal surgery has not as yet risen to the importance of a distinct branch in Germany. Professors Gusserow and Schrœder are professors of both obstetrics and gynecology, and perform all the operations coming under both heads. With proper precautions, I cannot see why a man who makes an "Emmet," or an amputation of the cervix, or who delivers a woman, should not also do a laparotomy. If he change his clothing and take a bath, as every one must do who attends a laparotomy in Berlin, and if he has a distinct set of instruments for his abdominal work, there can be little danger arising from his having come from a case of labor. Schroder and Martin have done splendid work, and yet they are busy at all hours of the day in the various departments of obstetrics and gynecology. Besides a perfect technique, they are both firm believers in antisepsis. Gusserow in diagnosis and pathology, Schroeder as a didactic lecturer, and Martin as an operator form a notable triumvirate.

\section{THE RELATION OF MIND TO MATTER. ${ }^{1}$}

\section{BY AMOS SAWYER, M.D.,}

$$
\text { OF HILLSBORO, IIL. }
$$

It is an evident fact that the materialistic theory is at the present day, among educated people, the popular one; but when, if it has not already reached its flow, the ebb sets in, it will be discovered that the members of the medical profession have in no small degree been responsible for its dissemination, as their preparatory studies necessitate the investigation of matter and its properties, and in the pursuit of this knowledge they lose sight of the fact that there is something immaterial in man, and that some of his acts are free. The same cause exists in all the branches of science, producing like effects; consequently scientific men are largely in the majority in the materialistic ranks, with the medical profession well represented, and all this in the face of the fact that every practitioner of medicine admits, that in numerous instances he recognizes the necessity for the treatment of the mind (whatever he may mean by the word) more than the body. Schiller said: "I abandoned surgery for philosophy and poetry because I found the wounds of the spirit were so much graver and more numerous than those of the flesh." The confidence with which the patient turns with almost every thought to his physician places him in a position next to God, and therefore the expression of an opinion carries with it a weight second to none; hence the relation is a responsible one.

The object, therefore, I have in view, is to attempt to prove that freedom of volition does exist, and that it is incompatible with matter; that man's actions

${ }^{1}$ Read before the Mississippi Valley Medical Society, Sept. 9, 1885. 
prove that he is not all matter, for in some of them he chooses, and therefore is free; and that the molecules of matter remain as the $y$ were created, unbroken and unworn. If I fail to make clear the position I have assumed; if my reasoning is defective, yet should it only awake in the mind of one of my hearers a train of thought that will enable him to clear away the cloud which prevents so many from distinguishing the material from the immaterial, the mind as something distinct from matter, though so intimately connected with it, I shall feel amply rewarded for my efforts.

Mind and matter are the two factors of the universe. Mind produces; matter is the product. And here, perhaps, it will be proper to explain what I mean when I make use of the terms, matter; a simple being, and a spiritual being. Matter has weight, and occupies space to the exclusion of other matter. It exists in three forms, solid, liquid and gaseous, and may be simple or compound. A simple being is not matter, but dependent upon matter, and therefore is material; as light, heat and electricity-forces in a body. A spiritual being is independent of, though incased in matter, and has an extrinsic dependency on matter because it depends upon the nervous system for the report of sensations, and depends upon the body for its compound life with the body, and God does not create it except in a body. Such an entity is spiritual, is immaterial. The light and heat of the sun is represented when wood or coal is consumed, and the force thus generated is that conserved in their formation, and clearly demonstrates that matter is dominated by a simple being (force)--it is the spirit of an otherwise motionless mass.

The materialist declares that there is nothing immaterial in man, that all our acts are necessitated and fated; in other words, we do only what we are obliged to do. What, then, is that mysterious life or entity created only in a body, and which manifests itself in memory, gratitude, love, hate, pride, and the belief in a life beyond the grave, if not something immaterial-spiritual? 'That we are free we know, for it is a fact of consciousness; human accountability rests on this truth; all laws are based upon it, from those governing the savage tribes, to those of the most civilized nations; for there can be neither reward or punishment, vice or virtue, where there is no freedom of action. Convince a jury that a man's actions are not free, and conviction is impossible. But apart from this, and that inward spiritual speech which alone greets that marvel of creative love-man-and which prompts him to do good and shun evil, and out of the wreck of every earthly hope bids him trust in that unseen creative power for rest in the realms above, there is other evidence inexplicable save by the admission of something not matter controlling our actions. Localized cerebration has been advanced by the materialists as an unanswerable argument in favor of their theory; the seat of intelligence being in the anterior and posterior convolutions of the cerebrum; and that memory has been located in the fissure of Sylvius, near the island of Reil; but is it memory? No! it is merely that portion of the brain where the mind receives, communicates, and expresses the recollections and opinions of subjects and objects; in other words, by certain nervous combinations it reproduces at this spot impressions received. But if I am wrong, and memory is merely the substance of the brain, how is it that in old age, when since youth the grey and white matter have been frequently renewed, we can retain the memory of childhood years? Is it written there as upon parchment? What a mental cyclone there must have been among the atoms of grey matter, if Spencer's theory is correct, and fearfully dangerous commotion in the necessarily rapid movements of mind-cells according to Hæckel's idea of cerebration, when Mithridates, king of Pontus, was calling each of his 80,000 soldiers by name! Scipio knew all the inhabitants of Rome; George III never forgot a face that he had once seen, or a name that he had once heard; when Lord Granville could repeat from beginning to end the New 'Testament in the original Greek, Bossuet could repeat the whole Bible, all of Horace, Virgil, Homer, and many other works. These are a few instances only of remarkable memories, or immense cerebral storage capacity. Can the substance of the brain store a lifetime's experience, and reproduce it at will? But stop! The will of what? It must be something superior to, as it controls matter. When we read something ludicrous, the mere sight or sound of the words (actions of matter) do not cause us to laugh, but it is the ideational change developed in something apart from matter which affects the risibilities; for if this act was merely mechanical, then every normal cerebral mass subjected to the same sight or sound (cause) should induce the same effect (consequence), but the fact that it does not, but frequently the opposite, excludes such a hypothesis. The same can be said of all our emotions. Why is it that we may become so accustomed to the striking of a clock as to become unconscious of its presence, if the impressions are made only on matter? For the vibrations of the air were transmitted to the delicate membrane of the ear as usual, and from thence to the brain by the natural mechanical and neurotic process; not a sound escapes it ; conseluently, if matter alone takes cognizance of sound, then, as it did make an impression on the substance of the brain, it should have recognized the number when it struck the hour; but the fact that it did not, proves that the cognition or intelligence is not composed of matter, but is distinct from it.

I am aware that some materialists claim that the recollection of past events is merely setting in motion again the molecules of grey matter, or, as Hreckel expresses it (Vol. i, pp. I 27), "the mind-cells which possess the capacity to feel, to act, to think," which originally produced the perception. (Query-What is that capacity? Evidently it is something superior to and distinct from the cell it controls.) But if this be true, I ask, what controls, and what sets these cells in motion again? For that we possess this power, every intelligent person must be conscious; the loss of it is insanity to that degree. Why is it that two persons, after viewing a subject or object, arrive at different conclusions? or why, by evidence or reasoning, change them, if the impressions made 
are simply movements or arrangements of the mindcells; or impressions on the grey substance of the brain? What has the power to effect the rearrangement of brain substance, and adjust the cells so as to form the new impression? Surely this is only another name for that intelligence which we call spiritual. If not, then the darkness is simply intensified by this kind of an explanation. It is strange how differently the cells arrange themselves, after viewing the same subject or object, in an educated and ignorant person, or even in two persons of equal mental calibre. The school-boy is not blameable when he has imperfect lessons; it is merely the wrong arrangement of the mind-cells, or the loss of "force" to call up the right ones; though the effect produced upon them by corporal punishment is wonderful, for after a thorough administration of this remedy, we usually find them better prepared at the next recitation. We may be in doubt which of two ways is the correct one to spell a word, but by writing it we can, from the appearance, quickly decide which is right. Now, as there must have been in this case two different arrangements of mind-cells formed in the brain, if this theory is correct, what was it that decided the question? We may recall some passage or verse committed to memory years ago, and although we can repeat it word for word, a doubt often arises as to its correctness which can only be removed by reference to the original. Now, what caused this feeling of doubt? It could not have been the mind-cells, for they were arranged right, and if they think, they must have known it. Why do we then, if this theory be true, condemn defaulters, murderers, thieves, etc.? It is merely the wrong arrangements of the mindcells which impelled them to commit the act; though most of them will admit, that had they heeded that "monitory voice" - that force or capacity - that something not matter, which warns us as we walk, and rebukes us when we stray, they would not have fallen. No, we do not inflict punishment upon machines, as this theory makes us out to be, but upon hearts, souls, characters, when they have been false to their Creator, to their fellow-men, and to themselves by the violation of the law which the natural exercise of their free-zwill would have prevented.

Dr. Zuckertort, the chess player, says, in explaining how he is able to play several games at the same time without seeing the board: "I have a way of photographing a board in my mind, and the boards being numbered, when one board is called, the photograph of the position of the men on the board comes instantly before my mind, while the last board disappears; I never see two boards before me for a single instant." Now, what is the power controlling that "force" by which this mind-cell shuttle is moved back and forth to the fissure of Sylvius in its proper time and place, if not something superior to, and apart from matter? For, if force acted alone upon matter, the boards would reappear in the inverse order of their formation, six, five, four, etc.; but the fact that they come as called, one, and five, and three, and six, is conclusive evidence that the simple being (force) is controlled by an intelligent, creative power superior to it, which we call mind (a spiritual being). The truth is, that in their attempt to explain these and kindred phenomena, the materialists are led to attribute to laws and actions of matter, what in reality are actions and laws of spirit.

That successful physicians, generals, merchant princes, and landed aristocrats must possess similar powers to those evidenced by Dr. Zuckertort in the game of chess, there can be no doubt, but if this phenomenon is due alone to the action of matter, then, as the quantity and quality of brain substance used in cerebration in these cases must be about the same, they should be able to change position with each other with equal success; just as a car constructed to carry ten tons of freight, will transport with equal ease and safety that weight of corn, coal, or any other substance; but that this is not the case with the brain we have convincing proof in the numerous individual instances we can all recall. This demonstrates that its movements are controlled by a spiritual being (mind) acting through a material substance, and that it is not matter that chooses what is agreeable and suitable for its development; for when this spiritual desire is disregarded, failure inevitably follows. If the brain be perfect in quantity, quality and construction, the psychical endosmosis and exosmosis emanating through such an instrument, with proper advantages, will place the possessor among the conceptive and accomplished of his day. Webster's brain would not have varied a single iota in weight or appearance had he remained an ignorant country farmer, but had that something not matter (mind) which marks out the path for, and urges us to follow through life, prompted him to become a chemist, an astronomer or a geologist, there is little doubt but that he would have become as renowned in that branch of science, as he did as a jurist and a statesman. We would not expect a man to make lumber with a hand-saw; or think of blaming the engineer because he could not make his engine draw 300 tons when its traction power was only 150 . It is exactly so with the mind in its relation to the brain.

The materialists assert, in proof of their theory, that we have no cognitions except such as are afforded us by our sensations, but that we cannot rely on our sensations because the object may not be as our sensations perceive it to be. What, then, do we know? Only that we are and that we feel something; hence we can never know what we are or what we feel. That this reasoning is false we must all acknowledge. To illustrate: if marble, or substances possessing similar properties, be brought in contact with the skin, the impression conveyed to the senses and the sensational understanding is that they must be colder than other substances, such as wood, etc., and this impression would remain, was there not a power apart from and controlling matter, which, regardless of the sensation, informs us that the coldness is illusive, and due to its greater capacity for the absorption of heat; in other words, it is a better conductor. Again, it is evidenced in traumatic pressure of the brain, for we find, after a long interval of insensibility, the mind at once resumes its function when the obstruction which prevented the machine (brain) from working is removed. Some twenty-five 
years ago, Dr. Brainard, of Chicago, removed a piece of depressed bone from the head of a sailor who, twelve months previously, had fallen from the rigging of a schooner and remained insensible up to that time. The moment the pressure was removed, the mind gave proof of its readiness for action by recalling the event, although the past year was a blank in his life. Another case, still more remarkable, occurred in Maine: The son of a miller, while standing on one side of the mill-pond, at a banter from his father, who was on the other side, shot at a snipe standing on a rock in the middle of the pond; the ball missed the bird and, glancing from the stone, struck the father in the forehead. He remained in an insensible condition for nearly two years, when a depressed piece of bone was removed, and the mind taking up the thread where it had been so suddenly broken, he exclaimed: "Zeek, you dog, you missed it;" thus proving that in the almost imperceptible in terval between the shot and the reception of the injury, the mind had mirrored the fact that the bird was unhurt, and had framed an answer for delivery. Force alone could act so instantaneously; but neither force or matter, alone or combined, could retain the knowledge of the event for such a length of time.

If I call a materialist's attention to my watch, and in explanation inform him that in strength in construction, beauty in design, and regularity of movement, the jewelled time recorder approximated so closely to perfection that, regardless of thermometric, barometric and electrical changes, the variation would be but the fraction of a second in six months, he would then naturally enough ask: Who made that watch? If I should reply, "No one made it; it made itself," would not this answer justly enough elicit the interrogation, "Is he an idiot, or insane?" The eighty-one stars in Orion have moved back and forth for thousands and thousands of years without collision or departure, for they move with a regularity and precision of which the description of the watch forms but a beggarly illustration. This infinite, endless motion of the stars, this magnificently majestic illuminated planetary procession, moving with a precision which enables us to foretell for years in advance where their shadows will fall, instinctively and intuitively, prompts the question, Who made them? If I reply "They had no maker, they made themselves," then, instead of pronouncing the sentence, " $\mathrm{He}$ is a fool, or lunatic," the materialist exclaims, "Behold an advanced scientist and philosopher!"

I ask the materialist how he accounts for the phenomenon of cerebration? Herbert Spencer answers, "The mind exists wherever gray matter is found, whether in the axis-cylinder of Purkinje, or the neoplasm of the cell itself; and whether found in the tentacle of the cuttle fish, the tail of a dog, or the brain of a man." Hæckel assures us that "the mind is composed of cells which possess the 'capacity' to will, to act, to think;" but here we find that they are acted on by some superior force controlling them, and are therefore merely instruments; for if $I$ ask, What do you mean by the word capacity? they answer, "We mean force." Now what is this peculiar force (something created only in a body), not possessed by other cells? That you believe or are convinced of the truth of your assertion I have no doubt; but this will not answer the purpose; how do you know, how can we become conscious that volition is due to the action of peculiar brain-cells, gray matter, or any other substance peculiar to the cerebral mass? Surely it cannot be accounted for in the composition of the material out of which they are constructed; certainly the different form of the cell will not explain it, therefore it remains a very pretty undemonstrable theory without any foundation of facts. That Hreckel was honest in his belief that he had discovered that the mind consists of peculiar shaped cells, and that Spencer thought that he had demonstrated that the mind was simply the gray matter wherever found, I would not question, for with their conception of it (as we are seldom more than we deem ourselves to be), they would naturally enough expect to find it as quickly in the tentacles of the cuttle fish, or a dog's tail, as in the brain of a man; though Spencer has never shown, nor have we any data that would warrant us in asserting, that a bob-tailed dog possessed less intelligence than before he was curtailed of so much of his mental faculties. With the evidence adduced, such a predicate would suggest that in his search to discover the origin of this mysterious force, he had exhausted his brain and arrived at this conclusion through an act of cerebration at the other end.

If you ask me, What is the mind? I would answer: That something created within us that can be used to control the voluntary actions of man, as evidenced in his ability to do good or evil; to seek that which is pleasurable and avoid what is painful; to choose the occupation best suited to his endowments; the recollection of names and the objects to which they belong; that which appreciates the character of the impressions received, which knowledge enables us to adopt means for the accomplishment of particular ends; that which forms conceptive ideas in the brain of man by which he moulds the other factor (matter) into forms which, but for this, would not exist; as works of art, and the inventions so necessary for success in peace or war, as well as in the struggle of civilization against barbarism. There is no other source whence they can come. In a word, every successful invention is an idea realized-it is the material construction of a mental conception, and which, but for this, would never have existed; it is this preëxisting form in the mind that guides the artist's and the artisan's hands; that made an Archimedes and an Angelo; and just as this psychical model is perfect or imperfect, distinctly or indistinctly seen, will the material form shadow forth more plainly than can be told in language. It is related of Michael Angelo that in explaining to a visitor at his studio what he had been doing at a statue since his previous visit, he said: "I have retouched this part, polished that; softened this feature; brought out that muscle; given some expression to this lip, and more energy to that limb." "But those are trifles," remarked the visitor. "It may be so," the artist replied, "but trifles make perfection, and perfection is no trifle." 
It is the mind that rules. It is this same factor which known to us; and still more obscure is the character enables us to look into the future as well as the past, and profit by the experience of those who have preceded us.

Now gray matter, or a so-called mind-cell, no matter what form it may assume, by which it is distinguished from other brain cells, cannot distinguish the phenomenon except as an instrument, because it is composed of matter, and matter can act only as it is acted on. The brain and nervous substance are similar in their chemical nature. The chief difference between the white and gray portion is in their structure, the former being composed of nerve-fibres alone, the latter containing, in addition to the nervefibres, interstitial matter and nerve-cells. They contain eighty per cent. of water, the solid matter consisting in part of a protein body, in part of a body which, by the action of acids, yields products similar to the viscous matter of the yolk of an eggr; a fatty crystalline acid which contains nitrogen and about one per cent. of phosphorus, named cerebric acid. Cholesterine is also present, and an oily, fatty acid containing phosphoric and oleic acid. Now what is there, singly or combined, in these substances which could possess the power "to will, to act, to think?" That they are composed of matter is proved by the fact that they can act only as they are acted on. For you may mix them all in the proper proportion, yet you cannot form organized brain substance; but were it possible to accomplish this feat, can we think for a moment that it could be made to perform the act of cerebration? No; for it would lack the pres: ence of that capacity, that force, that something not matter, which vitalizes and controls it. Just as a stream of oxygen and hydrogen gas, though they have a strong affinity for each other, may be mingled with impunity, but the mere presence of a piece of platinum sponge will cause them to combine, though the platinum is not changed in the slightest degree. This something encased in matter is the platinum for our body, and so long as it remains and the chemical elements are supplied, just so long does it perform its katalytic office, and the force thus generated acts as the motor for our various vital processes. It is true, that under certain circumstances we can take the human machine after the katalytic, entity has taken its flight, and by inducing artificial respiration molecular life will remain for a limited time; but this result is obtained by the exercise of an external, as before it was due to an internal, force; both genererated, however, in the same way. But that something, created for it, that we call life, can never be recalled, the somatic death removed, or the once intelligent being be made to respond in this world to inquiries. In volition, if it be regarded as the effect of chemical action, the same quantity produces results as different as the school-girl's musical composition and the masterpiece of a Mozart, a Raphael's conception of the Madonna and the daub of a sign painter. No quantity or quality of brain-matter ever generates a true idea, or a false one. Matter does not think, it does not feel; and how an impression upon the periphery of a nerve becomes transformed into a sensation is, as Professor Huxley remarks, utterly unof self-conscious intellection.

Finally, as materialism is the study of matter and its properties, it is essential for a materialist to be a chemist as well as a physiologist, in order to investigate the subject intelligently; yet how few of the members of this school possess these necessary requirements? Chemistry informs is that everything in nature, whether simple or compound, dejends for what it is, upon that which is not. It shows us, among a host of other things, that $\mathrm{C}_{4} \mathrm{H}_{8} \mathrm{O}_{2}$, with the atoms grouped differently, produces the disagreeable smell of rancid butter and the agreeable odor of ripe apples; $\mathrm{C}_{6} \mathrm{H}_{5} \mathrm{O}_{5}$, for like reasons, forms the different bodies, sugar, starch, and wood; but the force that grouped them remains an unknown factor. It answers the question, What is the quantity, quality, arrangement and the mechanism of the atoms which give form to animals and plants from conception to maturity and death? but it is utterly unable to ex plain why, what or whence came that mysterious microscopic atom of energy, the presence of which gave birth alike to the giant oak, the modest blade of grass, the huge mastodon and the infinitisimal infusoria. It speaks to us of design in language not to be misunderstood, when it shows that every organic and inorganic substance is composed of an undeviating combination of atoms held together by a force nut inherent in any one or the combination; for if we reduce an organic substance to its ultimate atoms, collect the oxygen, hydrogen, carbon, nitrogen, etc., we are incapable of putting them together again because we cannot generate the life-force which originated it. Chemistry tells us the composition of common salt, but it cannot explain why this healthful compound is formed by the union of two deadly poisons. The physiologist has located memory and the receptive points in the brain of man and that stimulus which induces many of his volitional acts, but what it is that retains and reproduces-that wills-it cannot solve. Physiology furnishes the proof that growth and decay, waste and repair, are simply the chemical processes of secretion and excretion, or an endosmotic and exosmotic action; but how the atoms should be so grouped as to form a microscopic thread of matter containing all the necessary foundation stones upon which to build a little image of the animal within whom it was deposited, with all its varied and intricate organs, is a physiological enigma, nor have we any data for speculating as to its origin. It has demonstrated that the function of the nervous system is to associate the different parts of the body; and it informed us as to the interval of time between the application of stimulus to one organ and the excitation of activity in another; but it is arrested when it attempts to explain what it is that appreciates the character of the impressions received.

Therefore we reason: if the faculties of memory, gratitude, love, hate and pride, the power of selfcontrol, of looking into the future as well as the past, of reasoning from cause to effect, is simply the effect of chemical combinations, then the same physiological properties of the hemispheres of the brain in man should be reproduced in the lower animals, as 
well as in all organic substances where this same process is constantly at work, and upon which their growth and existence depends. But the absurdity of such reasoning is shown when we see that, although the chemist has determined, with the utmost accura$c y$, of what elements the proximate constituents of plants are composed, and by what proportions by weight, he has never yet succeeded in reconstructing these constituents from their elements. We cannot imitate, ly art, the workings of nature in living plants as we can do most perfectly in inorganic chemistry. Certain it is that if the act of volition is due to molecular life, then as this does not cease at the moment of death, but can be maintained for a limited time thereafter, then while the cause remains the same effect should manifest itself, but the fact that with somatic death they cease, proves that it is not consequent on or dependent upon chemical change, but is distinct from it; in other words, it is dependent upon some departed superior force or cause. Thus we have traveled over a scientific path to say what the mind is not; what it is in its essence, will ever remain, in this world, a mystery. We also see that the materialist is encompassed with fears and doubts unknown to the Christian; and if, as Hrekel claims, "the theory of the creation is a blind belief," how much more so is that of materialism, "the scientific theory of evolution;" in the former we follow a bright ray of light, while the latter is impenetrable darkness.

In conclusion, then, we know that the organic portion of all living organisms is formed by chemical combinations, induced by a katalytic something, and governed by certain immutable laws by which the atoms of matter are so arranged as to give the distinctive form and size in accordance with the microscopic foundation of the sperm model deposited in its proper creative receptacle. We know that chemical combinations do not, nor can they be made to, give origin to life in any of its phases; and, therefore, in accordance with an axiom in reasoning, we conclude that this must always have been the case, and as matter cannot bestow upon its combinations that which it does not possess, that organic life must be consequent on and dependent upon that which gave it birth-something not matter; hence the materialist should change his name as well as his field, for he must exclude matter in his search for psychical properties and action.

We must all admit that the celebrated atheist and scientist, Du Bois-Reymond, was right when he said: "With regard to the enigma of the physical world, the investigator of nature has long been wont to utter his 'Ignoramus' (we know not) with manly resignation. . . As regards the enigma of what matter and force are, and how they are to be conceived, he must resign himself once for all to the far more difficult confession - 'Ignorabimus' (we shall never know)." We may not be able to give at once an intelligent explanation of all the physical phenomena coming under ohservation, but we have reason to believe that in the future, as in the past, a solution will be found.

\section{ADDRESS IN MEDICINE DELIVERED BEFORE THE}

\section{NEBRASKA STATE MEDICAL SOCIETY,}

MAY, 1885.

\author{
BY ALFRED SHIPMAN, M.D.,
}

OF YLATTSMOUTH, NEB.

The successful treatment of the various diseases which affict mankind is based upon sound conception of pathology, while pathology has for its basis an absolutely correct knowledge of physiology. In the formation of pathology, physiology is indispensable. In order to reach a correct diagnosis we must have a correct system of pathology. Were the physiological conditions and principles always clearly known and understood, our system of pathology might approach perfection, but physiology is not an exact science, perhaps never will be. Absolute knowledge in regard to all and every physiological state and condition may never be attained. Physiology may be said to be one of the least mature, because one of the most complex of the sciences. Therefore our pathology may remain defective, and if so, the practice of medicine will continue to be an imperfect art, medicine will continue to be a progressive but not an exact science.

I am one who believes that medicine is a progressive science, and that in many of its departments it already approaches a precision scarcely realized by many practitioners. Contrasting the difference in the practice of to-day with the practice current even twenty-five years ago, and who will say no advance has been attained. Reduce the time to a review of the progress made during the past society year, and even during this short period the accumulation of material for consideration covers such a vast field of thought that to properly present the same for your consideration in the short space of time allotted to us becomes an impossibility. I am free to say that there is a fashion among many of regarding change of any kind, progress. A simple change in the manner of treating a particular disease is not always evidence of medical progress. We sometimes follow false lights, but not for any great length of time.

Actual improvements, and progress in medical practice are the result of careful research. Patient investigation, careful physiological research, and abundant experimentation furnish the ground work for all forms of advancement in our art. The over confident assertion of one man may prove nothing, but the co-joined experience of many physicians may establish a principle in practice. From that day when the fathers in medicine began to record their experience and relate their plans of treatment, down to this, our day, medicine has been progressive. Although it may not take the recorded experience of thousands to establish a period in practice, yet it is necessary for each individual member of the profession to give voice to his convictions in order that what little knowledge he may have gleaned may become useful to the profession at large.

It is the duty of every physician to patiently, persistently, and scientifically investigate those diseases he is called upon to treat. In no other way can he 